\title{
Effect of a CoFeB layer on the anisotropic magnetoresistance of
} $\mathrm{Ta} / \mathrm{CoFeB} / \mathrm{MgO} / \mathrm{NiFe} / \mathrm{MgO} / \mathrm{CoFeB} / \mathrm{Ta}$ films

\section{Minghua $\mathrm{Li}^{1 *)}$, Hui Shi ${ }^{1+}$, Yuegang Dong ${ }^{1}$, Lei Ding ${ }^{2}$, Gang Han ${ }^{1}$, Yao Zhang $^{1}$,Ye Liu ${ }^{1}$, Guanghua Yu ${ }^{1}$,}

${ }^{1}$ Department of Material Physics and Chemistry, University of Science and Technology Beijing, Beijing 100083, People's Republic of China

${ }^{2}$ School of Materials and Chemical Engineering, Hainan University, Haikou 570228, People's Republic of China

\begin{abstract}
The anisotropic magnetoresistance (AMR) and magnetic properties of $\mathrm{NiFe}$ films can be remarkably enhanced via $\mathrm{CoFeB}$ encapsulation. In the case of an ultrathin NiFe film having a $\mathrm{Ta} / \mathrm{CoFeB} / \mathrm{MgO} / \mathrm{NiFe} / \mathrm{MgO} / \mathrm{CoFeB} / \mathrm{Ta}$ structure, the $\mathrm{CoFeB} / \mathrm{MgO}$ layers suppressed the formation of magnetic dead layers and the interdiffusions and interface reactions between the $\mathrm{NiFe}$ and Ta layers. The AMR reached a maximum value of $3.56 \%$ at $450{ }^{\circ} \mathrm{C}$. More importantly, a single $\mathrm{NiFe}(111)$ peak can be formed resulting in higher AMR values for films having $\mathrm{CoFeB}$ encapsulation. This enhanced AMR also originated from the significant specular reflection of electrons owing to the crystalline $\mathrm{MgO}$ layer, together with the sharp interfaces with the NiFe layer. These factors together resulted in higher AMR and improved magnetic properties.
\end{abstract}

Keywords: Anisotropic magnetoresistance (AMR); NiFe; CoFeB; Annealing; X-ray diffraction (XRD); High-resolution transmission electron microscopy (HRTEM).

\footnotetext{
*) Corresponding author. E-mail address: mhli@ ustb.edu.cn

+ Co-author
} 


\section{Introduction}

In the last few decades, plenty of work has been devoted to anisotropic magnetoresistance (AMR) thin films, which have promising applications as magnetic sensors and detectors. AMR sensors have vast potential for information processing, automation, aerospace, navigation and military applications[1-6]. AMR sensors have attracted much attention owing to their high sensitivity, small volume and excellent reliability characteristics. AMR thin films can be deposited on silicon substrates, being directly embedded in integrated circuits. Thus, an integrated assembly of magnetic sensors and other circuit units can be achieved. AMR sensors are also easily matched with an electrical circuit compared with other sensors such as Hall devices and semiconductor magnetoresistors.

$\mathrm{NiFe}$ (Permalloy) is the best material for use in AMR devices due to its large AMR amplitude and magnetic softness. The typical sensing component contains a $\mathrm{Ta} / \mathrm{NiFe} / \mathrm{Ta}$ structure for desired application performance. A thickness of $10 \mathrm{~nm}$ or less is desirable for $\mathrm{NiFe}$ films to diminish the demagnetisation effect. However, the AMR decreases rapidly with decreased NiFe thickness[7]. For $\mathrm{Ta} / \mathrm{NiFe}(10 \mathrm{~nm}) / \mathrm{Ta}$ films, the AMR is about $1.0 \%-2.0 \%$, depending on the experimental conditions. How to best enhance the AMR in NiFe films with good thermal stability has become an important issue. Liu measured an AMR ratio of $2.92 \%$ for the $\mathrm{Ta} / \mathrm{NiFe}(15 \mathrm{~nm}) / \mathrm{Ta}$ trilayer. However, for Ta/Pt/NiFe $(15 \mathrm{~nm}) / \mathrm{Pt} / \mathrm{Ta}$ films, the AMR ratio reaches a maximum value of about $3.21 \%$ at a Pt layer thickness of $0.15 \mathrm{~nm}$ [8]. Ding reported that the AMR reaches a maximum value of $3.10 \%$ after $380{ }^{\circ} \mathrm{C}$ annealing for $\mathrm{Al}_{2} \mathrm{O}_{3}$ encapsulated in a 10-nm NiFe film[9]. Wang reported the AMR value to reach a maximum of $3.5 \%$ for the $\mathrm{Ta} / \mathrm{NiFe}(15 \mathrm{~nm}) / \mathrm{Ta}$ trilayer with a substrate temperature of $400{ }^{\circ} \mathrm{C}[10]$

High AMR values and thin thicknesses are both necessary for the practical applications of NiFe films. Permalloy properties can be optimized by appropriate buffer layers and annealing, although the annealing process may led to the interdiffusions and interface reactions of thin films, thereby damaging their properties [11,12]. In the case of $\mathrm{Ta} / \mathrm{NiFe} / \mathrm{Ta}$ films, magnetic dead layers are present at the $\mathrm{Ta} / \mathrm{NiFe}$ and $\mathrm{NiFe} / \mathrm{Ta}$ interfaces, decreasing the effective thickness of the NiFe layer and thus resulting in poor properties [13]. As reported by 
Ding, the $\mathrm{AMR}$ of $\mathrm{NiFe}$ films with $\mathrm{Ta} / \mathrm{MgO} / \mathrm{NiFe} / \mathrm{MgO} / \mathrm{Ta}$ structure can be remarkably enhanced via $\mathrm{MgO}$ encapsulation. The $\mathrm{MgO}$ layers suppressed the formation of the magnetic dead layers and prevented the interdiffusions between the NiFe and Ta layers. The higher magnetoresistance (MR) ratio and sensitivity originated from the significant specular reflection of electrons owing to the crystalline $\mathrm{MgO}$ layer, together with the sharp interfaces between the $\mathrm{MgO} / \mathrm{NiFe}$ layers[14]. Bae's group reported that $\mathrm{MgO}$ is poly-crystalline when as deposited in $\mathrm{CoFeB} / \mathrm{MgO} / \mathrm{CoFeB}$ structures. After annealing at $340{ }^{\circ} \mathrm{C}$, it exhibits a better crystallised state with fairly smooth interfaces between $\mathrm{MgO}$ and $\mathrm{CoFeB}$ [15]. All the works described above imply that $\mathrm{MgO}$ deposited on $\mathrm{CoFeB}$ would significantly enhance the crystallization of the former while facilitating the formation of smooth interfaces. This work was aimed to enhance the crystallization of $\mathrm{MgO}$ by inserting a $\mathrm{CoFeB}$ layer to increase the AMR and magnetic properties of NiFe thin films. The structure of the film was $\mathrm{Ta}(5$ $\mathrm{mm}) / \mathrm{CoFeB}(\mathrm{t}) / \mathrm{MgO}(3 \mathrm{~nm}) / \mathrm{NiFe}(10 \mathrm{~nm}) / \mathrm{MgO}(3 \mathrm{~nm}) / \mathrm{CoFeB}(\mathrm{t}) / \mathrm{Ta}(3 \mathrm{~nm})$.

\section{Materials and methods}

Samples with a $\mathrm{Ta}(5 \quad \mathrm{~nm}) / \mathrm{CoFeB}(t) / \mathrm{MgO}(3 \quad \mathrm{~nm}) / \mathrm{NiFe}(10 \quad \mathrm{~nm}) / \mathrm{MgO}(3$ $\mathrm{nm}) / \mathrm{CoFeB}(t) / \mathrm{Ta}(3 \mathrm{~nm})$ structure were deposited onto corning glass substrates of $22 \times 22$ $\mathrm{mm}^{2}$ via magnetron sputtering at a base pressure of $3.0 \times 10^{-8}$ Torr and a sputtering pressure of 3 mTorr of $99.99 \%$ Ar gas, with $t$ varying from 0 to $3 \mathrm{~nm}$. The substrates were rotated at 40 rpm during deposition to ensure uniform film thickness. A magnetic field of $25 \mathrm{kA} / \mathrm{m}$ was applied parallel to the film planes to induce NiFe easy axis during deposition. Ta, $\mathrm{NiFe}$ and $\mathrm{CoFeB}$ were deposited by $\mathrm{DC}$ sputtering, whereas $\mathrm{MgO}$ was deposited via RF sputtering. After deposition, the samples were annealed at different temperatures $\left(400\right.$ and $\left.450{ }^{\circ} \mathrm{C}\right)$ for 1 $\mathrm{h}$ and $2 \mathrm{~h}$ in a vacuum furnace without external magnetic field under a pressure of $4 \times 10^{-7}$ Torr. The MR of the thin films was measured by the four-probe method (probe current $=1$ $\mathrm{mA}$ ). The magnetic properties were measured by a physical properties measuring system (PPMS), and the structure of the samples was characterized by X-ray diffraction (XRD) and the high-resolution transmission electron microscopy (HRTEM). 


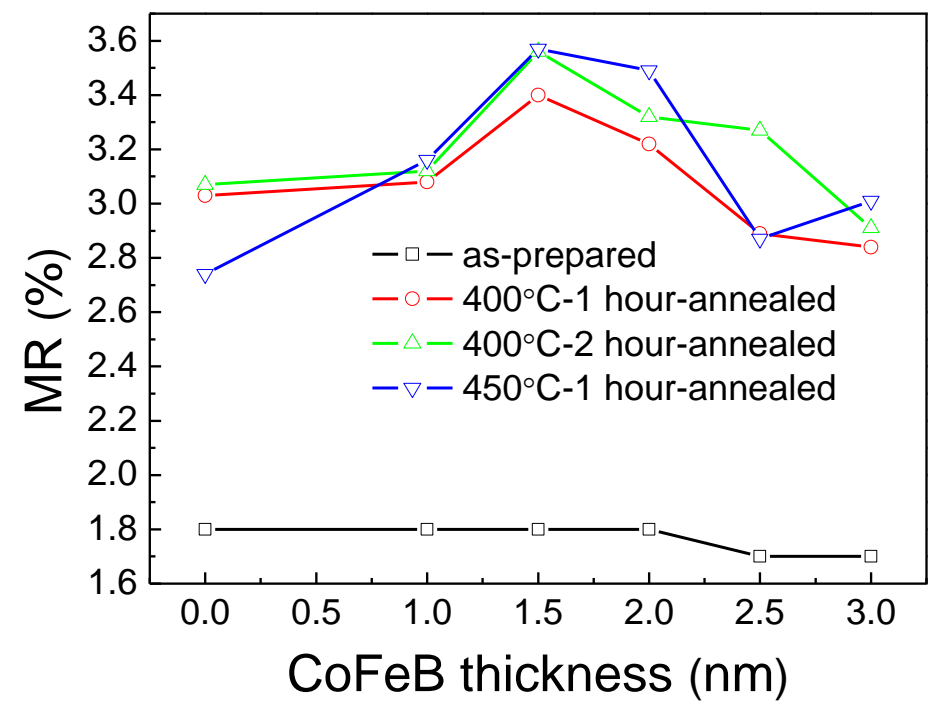

Fig. 1. The dependence of $\mathrm{CoFeB}$ thickness dependence on $\mathrm{MR}$ for $\mathrm{Ta}(5 \mathrm{~nm}) / \mathrm{CoFeB}(\mathrm{t}) / \mathrm{MgO}(3$ $\mathrm{nm}) / \mathrm{NiFe}(10 \mathrm{~nm}) / \mathrm{MgO}(3 \mathrm{~nm}) / \mathrm{CoFeB}(\mathrm{t}) / \mathrm{Ta}(3 \mathrm{~nm})$ before and after the annealing

\section{Results and discussion}

Figure 1 shows $\mathrm{MR}$ of $\mathrm{Ta}(5 \mathrm{~nm}) / \mathrm{CoFeB}(t) / \mathrm{MgO}(3 \mathrm{~nm}) / \mathrm{NiFe}(10 \mathrm{~nm}) / \mathrm{MgO}(3$ $\mathrm{nm}) / \mathrm{CoFeB}(t) / \mathrm{Ta}(3 \mathrm{~nm})$ thin films as a function of the CoFeB thickness at different annealing temperatures. In the case of the as-deposited film, MR remained nearly constant (ca. $1.8 \%$ ) with the CoFeB thickness. However, it slightly decreased at a CoFeB layer thickness of 2.5 nm. Thus, the CoFeB layer did not have a significant effect on the MR of the as-deposited films. After annealing at 400 and $450{ }^{\circ} \mathrm{C}$ at varying times $(1 \mathrm{~h}$ and $2 \mathrm{~h}$ ), the MR ratio of the thin films increased significantly. Maximum MR values were achieved for films having CoFeB layers of $1.5 \mathrm{~nm}$ in thickness, and a further increase in the CoFeB layer thickness resulted in lower MR. For example, MR ratio peaked at $3.56 \%$ for the film annealed at $450{ }^{\circ} \mathrm{C}$, with this value being $30 \%$ higher than the maximum MR of the film annealed at $450{ }^{\circ} \mathrm{C}$ without $\mathrm{CoFeB}$ layer $(2.74 \%)$. These results also indicate that a proper increase of the annealing duration may result in higher MR ratio values of thin films. In particular, the existence of a $\mathrm{CoFeB}$ layer after annealing apparently enhanced the MR values for $\mathrm{Ta} / \mathrm{CoFeB} / \mathrm{MgO} / \mathrm{NiFe} / \mathrm{MgO} / \mathrm{CoFeB} / \mathrm{Ta}$ thin films.

According to other reports, maximum $\mathrm{MR}$ values have been achieved for 
$\mathrm{Ta} / \mathrm{MgO} / \mathrm{NiFe} / \mathrm{MgO} / \mathrm{Ta}$ films annealed at $400{ }^{\circ} \mathrm{C}$ or $450{ }^{\circ} \mathrm{C}[14]$. In our report, the AMR reaches a maximum value in $\mathrm{Ta} / \mathrm{MgO} / \mathrm{NiFe} / \mathrm{MgO} / \mathrm{Ta}$ films after annealing at $400{ }^{\circ} \mathrm{C}$. However, the films with a $\mathrm{CoFeB}$ layer have a higher AMR than films without a $\mathrm{CoFeB}$ layer, and they are thermally stable up to $450{ }^{\circ} \mathrm{C}$. When the annealing duration is further increased from $1 \mathrm{~h}$ to $2 \mathrm{~h}$, the AMR values show just a slight increase for films annealed at $400{ }^{\circ} \mathrm{C}$. This result shows that the annealing duration has little influence when the duration is extended for longer than 1 hour. In contrast, the MR ratio with the $\mathrm{Ta} / \mathrm{NiFe} / \mathrm{Ta}$ structure decreased dramatically with an increase in annealing temperature.

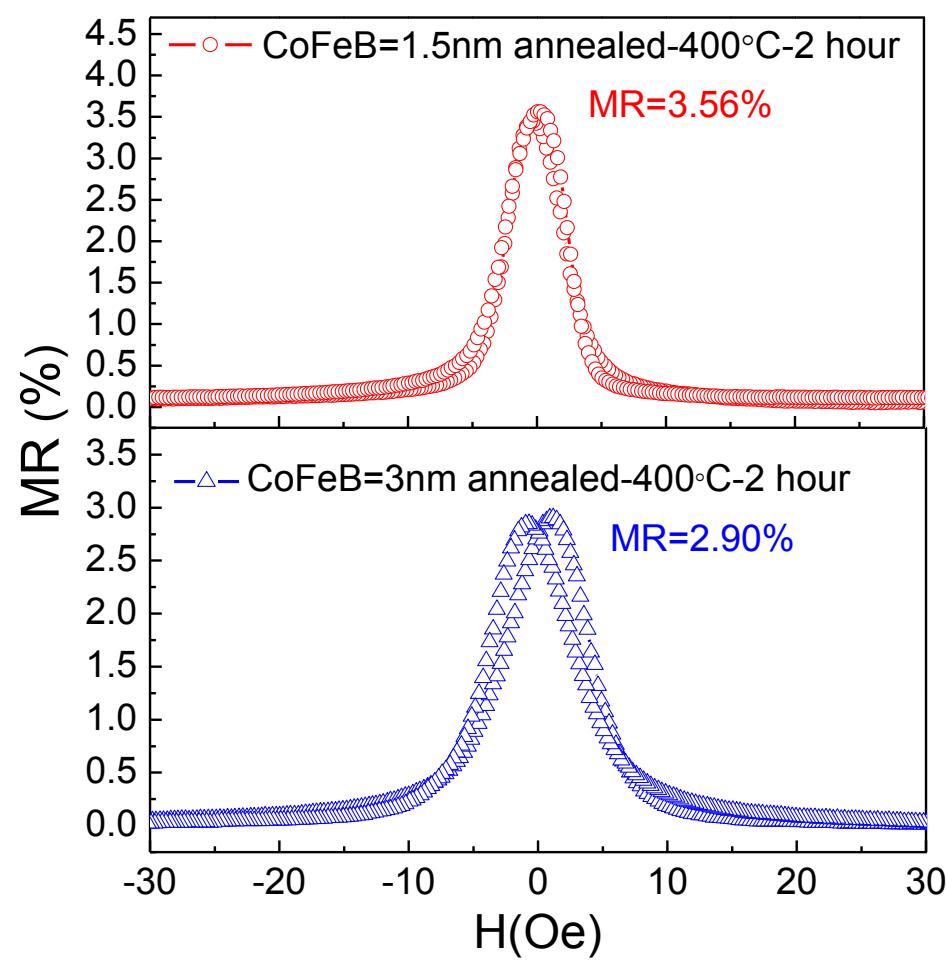

Fig. 2. MR-H curves of $\mathrm{Ta}(5 \mathrm{~nm}) / \mathrm{CoFeB}(\mathrm{t}) / \mathrm{MgO}(3 \mathrm{~nm}) / \mathrm{NiFe}(10 \mathrm{~nm}) / \mathrm{MgO}(3 \mathrm{~nm}) / \mathrm{CoFeB}(\mathrm{t}) / \mathrm{Ta}(3$ nm) thin films with $\mathrm{CoFeB}$ thicknesses of 1.5 and $3 \mathrm{~nm}$ after annealing at $400{ }^{\circ} \mathrm{C}$ for $2 \mathrm{~h}$.

Figure 2 shows the MR-H curves of thin films having $\mathrm{CoFeB}$ layers of 1.5 and $3 \mathrm{~nm}$ after annealing at $400{ }^{\circ} \mathrm{C}$ for $2 \mathrm{~h}$. The maximum MR ratio reached $3.56 \%$ for the film with a 1.5-nm $\mathrm{CoFeB}$ layer, representing an increase of $30 \%$ compared to the film without $\mathrm{CoFeB}$ (2.74\%). An increase in the CoFeB layer thickness to $3 \mathrm{~nm}$ resulted in a lower MR ratio 
(2.90\%) and an MR-H curve with double peaks indicative of thin films with large coercivities $\left(H_{c}\right)$. The saturation field (Hs) is about 5 Oe for the sample with a $1.5-\mathrm{nm}$ CoFeB layer. In contrast, the sample with a 3-nm CoFeB layer exhibited poor anisotropy, with 15 Oe Hs. These results show that the existence of the $\mathrm{CoFeB}$ layer enhanced the MR ratio of the thin films up to a certain thickness value above which this parameter and the magnetic properties and MR ratio of the thin films were negatively affected.

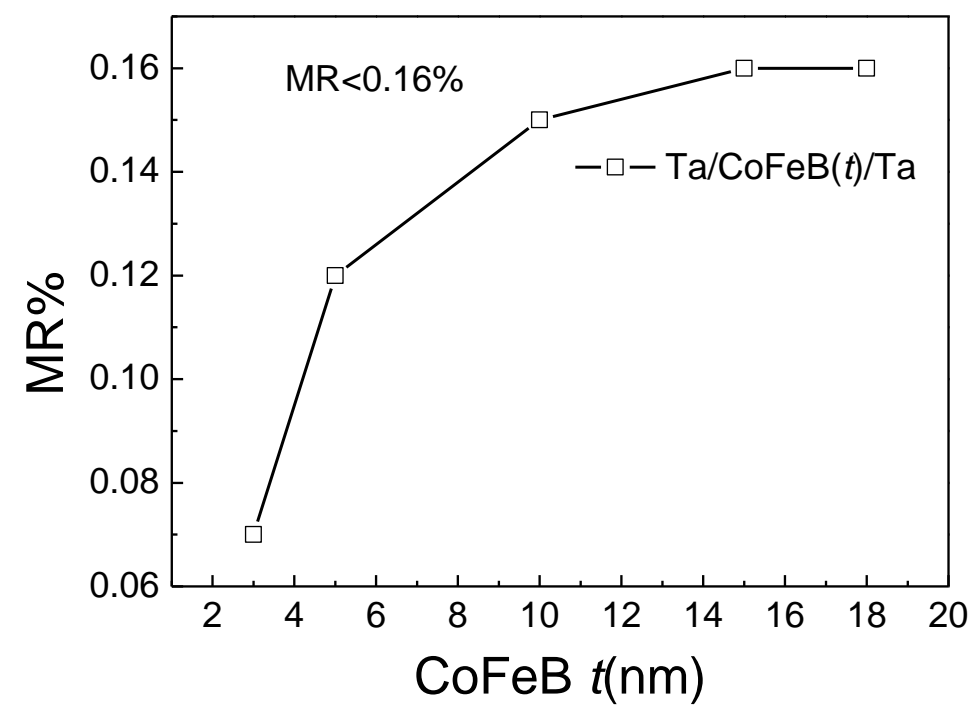

Fig. 3. MR ratio as a function of the $\mathrm{CoFeB}$ layer thickness for $\operatorname{Ta}(5 \mathrm{~nm}) / \mathrm{CoFeB}(\mathrm{t}) / \mathrm{Ta}(3 \mathrm{~nm})$ thin films annealed at $400{ }^{\circ} \mathrm{C}$ for $2 \mathrm{~h}$.

Considering that $\mathrm{CoFeB}$ is a type of ferromagnetic material, further measurements are needed to exclude the possible contribution of $\mathrm{CoFeB}$ in the overall MR ratio of $\mathrm{Ta} / \mathrm{CoFeB} / \mathrm{MgO} / \mathrm{NiFe} / \mathrm{MgO} / \mathrm{CoFeB} / \mathrm{Ta}$ thin films. Figure 3 shows the MR ratio as a function of the $\mathrm{CoFeB}$ layer thickness for $\mathrm{Ta}(5 \mathrm{~nm}) / \mathrm{CoFeB}(t) / \mathrm{Ta}(3 \mathrm{~nm})$ thin films annealed at $400{ }^{\circ} \mathrm{C}$ for $2 \mathrm{~h}$. The MR ratio increased with the CoFeB thickness and levelled off $(0.16 \%)$ at $\mathrm{CoFeB}$ thicknesses higher than $14 \mathrm{~nm}$. MR ratios of $0.07 \%$ and $0.14 \%$ were obtained for thicknesses of 3 and $6 \mathrm{~nm}$, respectively. The contribution of the $\mathrm{CoFeB}$ layer to the overall MR ratio of the $\mathrm{Ta} / \mathrm{CoFeB} / \mathrm{MgO} / \mathrm{NiFe} / \mathrm{MgO} / \mathrm{CoFeB} / \mathrm{Ta}$ thin films was $<0.2 \%$ and even lower $(0.1 \%)$ for CoFeB layers with a thickness of $3 \mathrm{~nm}$. The $\mathrm{MR}$ ratio for $\mathrm{Ta} / \mathrm{MgO} / \mathrm{CoFeB} / \mathrm{Ta}$ structure has been measured. The MR is $0.24 \sim 0.40 \%$, which is a slightly higher than that of the 
$\mathrm{Ta} / \mathrm{CoFeB} / \mathrm{Ta}$ since the $\mathrm{MgO}$ is non-magnetic material. As a result, the direct contribution of $\mathrm{CoFeB} / \mathrm{MgO}$ layers to the overall $\mathrm{MR}$ ratio of the thin films can be considered to be negligible.

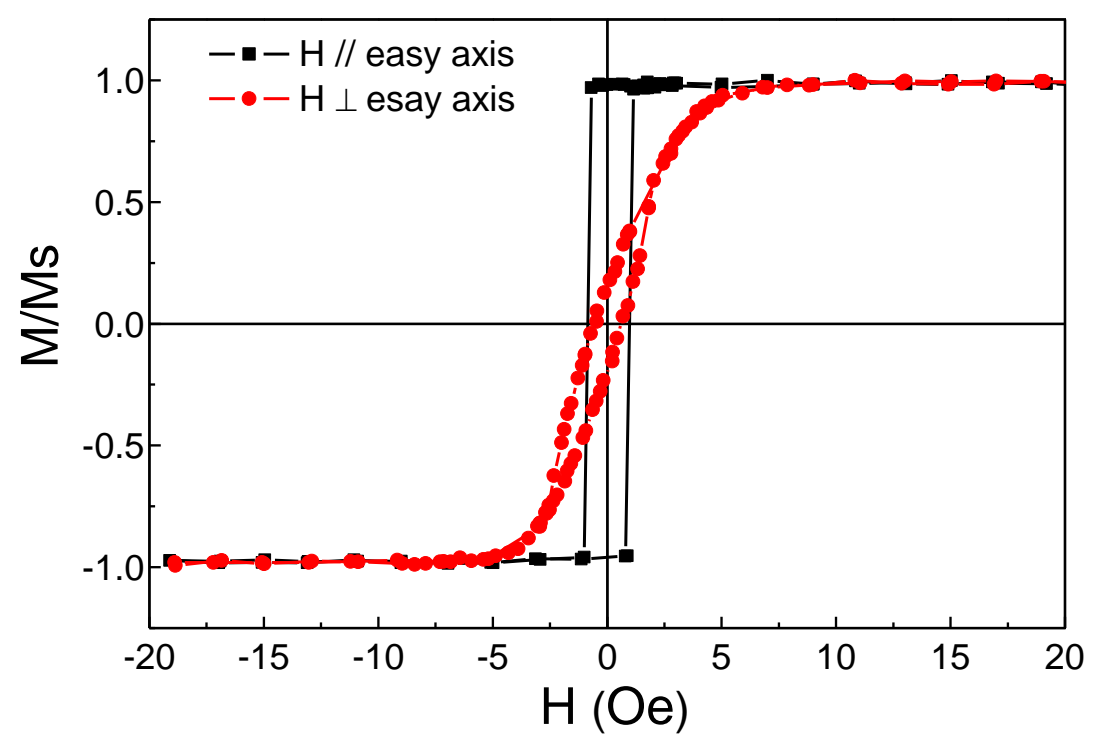

Fig. 4. Hysteresis loop of thin films with a $1.5-\mathrm{nm} \mathrm{CoFeB}$ insertion layer after annealing at $400{ }^{\circ} \mathrm{C}$ for $\mathbf{2} \mathbf{h}$.

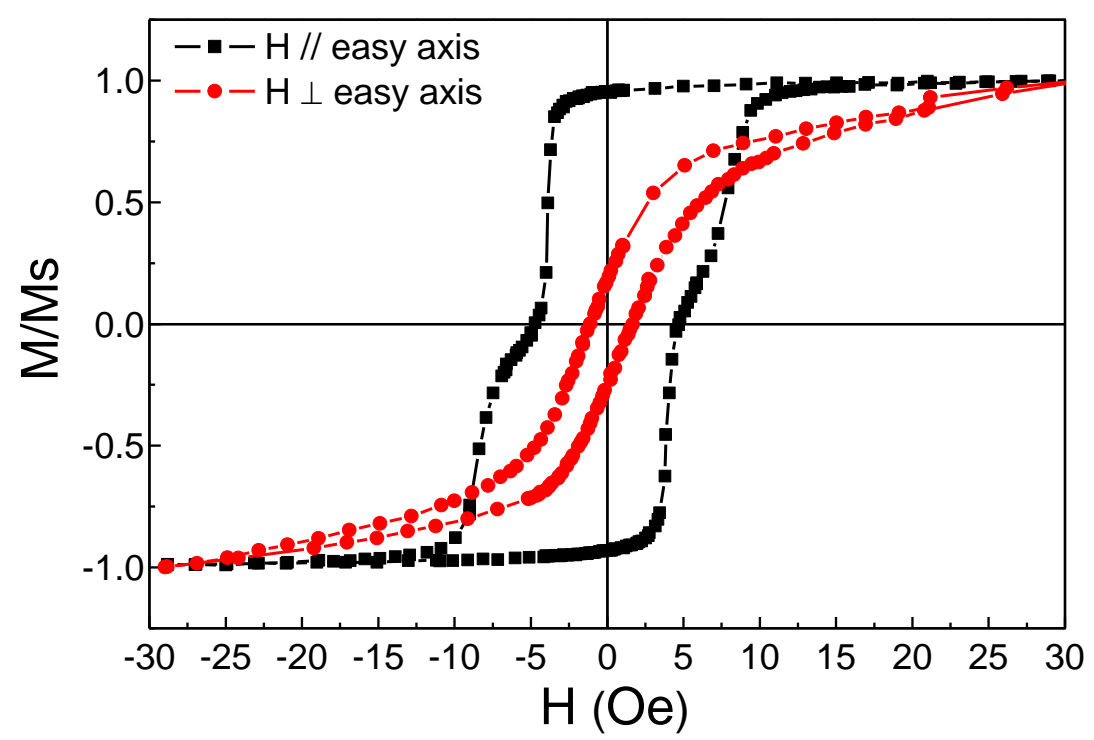

Fig. 5. Hysteresis loop of thin films with a 3-nm CoFeB layer after annealing at $400{ }^{\circ} \mathrm{C}$ for $2 \mathrm{~h}$.

The hysteresis loops of the samples after annealing were measured by PPMS to study the 
influence of the $\mathrm{CoFeB}$ layer on the magnetic properties of $\mathrm{Ta} / \mathrm{CoFeB} / \mathrm{MgO} / \mathrm{NiFe} / \mathrm{MgO} / \mathrm{CoFeB} / \mathrm{Ta}$ thin films. Figures 4 and 5 show the hysteresis loops of thin films having 1.5- and 3-nm CoFeB layers after annealing at $400{ }^{\circ} \mathrm{C}$ for $2 \mathrm{~h}$. The sample with a 1.5-nm CoFeB layer maintained its soft magnetic and uniaxial anisotropic performance after annealing at $400{ }^{\circ} \mathrm{C}$ for $2 \mathrm{~h}$, with $H_{c}$ being $<2$ Oe and a saturation field $\left(H_{s}\right)$ being $<5$ Oe. In contrast, the sample having a 3-nm CoFeB layer showed poor anisotropy after annealing at $400{ }^{\circ} \mathrm{C}$ for $2 \mathrm{~h}$, with $H_{c}=5$ Oe and $H_{s}$ being <15 Oe. Notably, two magnetic phases were observed in the hysteresis loop (easy axis) of the latter sample. This may be attributed to the total thickness of the CoFeB layer $(6 \mathrm{~nm})$ being of the same order of magnitude as the thickness of the NiFe layer $(10 \mathrm{~nm})$, with $\mathrm{CoFeB}$ contributing significantly to the overall magnetism of the thin films. CoFeB has different magnetic properties compared with NiFe. Thus, $\mathrm{CoFeB}$ forms another magnetic phase with different types of magnetic domains, thereby destroying the uniaxial anisotropy of the material. As a result, $H_{c}, H_{s}$ and the uniaxial anisotropy (which are stable at a CoFeB thickness of $1.5 \mathrm{~nm}$ ) rapidly deteriorated when the CoFeB thickness reached $3 \mathrm{~nm}$, degrading the MR properties and the MR-H curve of the thin films.

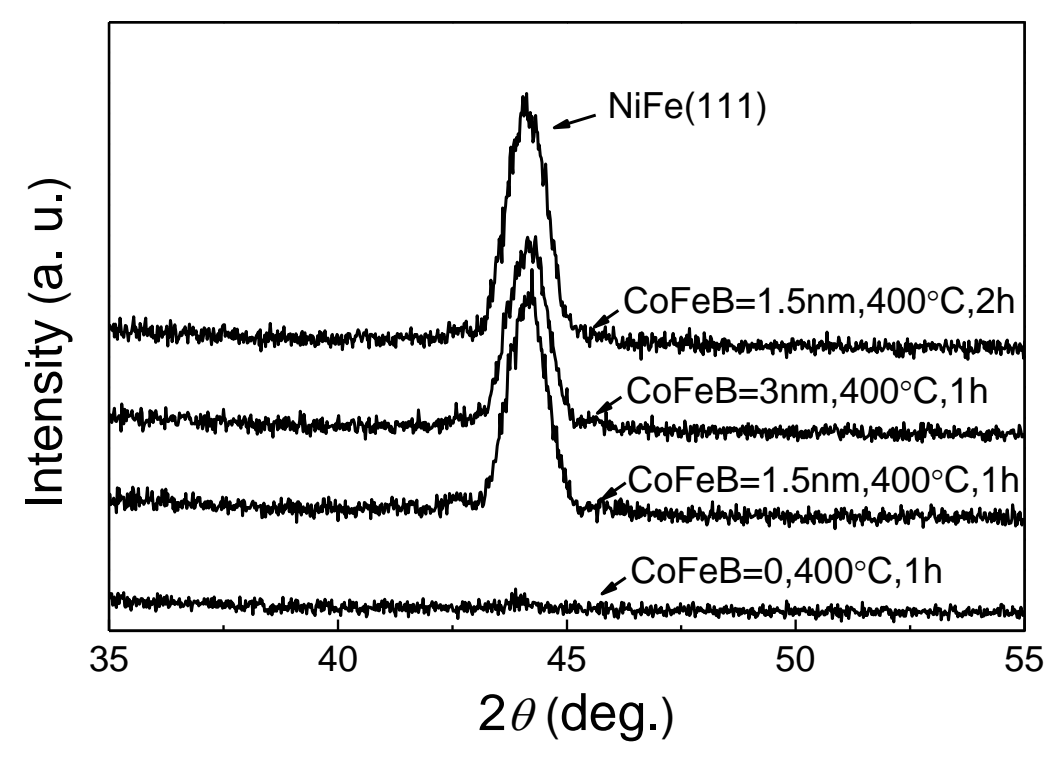

Fig. 6. XRD patterns of $\mathrm{Ta}(5 \mathrm{~nm}) / \mathrm{CoFeB}(\mathrm{t}) / \mathrm{MgO}(3 \mathrm{~nm}) / \mathrm{NiFe}(10 \mathrm{~nm}) / \mathrm{MgO}(3 \mathrm{~nm}) / \mathrm{CoFeB}(\mathrm{t}) / \mathrm{Ta}(3$ nm) thin films after annealing. 
Structural analysis of the films while varying the CoFeB thickness was performed by XRD to gain insight into the reasons behind the enhancement of AMR. Figure 6 shows the XRD patterns of $\mathrm{Ta}(5 \mathrm{~nm}) / \mathrm{CoFeB}(t) / \mathrm{MgO}(3 \mathrm{~nm}) / \mathrm{NiFe}(10 \mathrm{~nm}) / \mathrm{MgO}(3 \mathrm{~nm}) / \mathrm{CoFeB}(t) / \mathrm{Ta}(3$ $\mathrm{nm}$ ) thin films after annealing at $400{ }^{\circ} \mathrm{C}$. No apparent peaks were found in the film without CoFeB. A single $\mathrm{NiFe}(111)$ peak was observed for all the films having a $\mathrm{CoFeB}$ layer, and the intensity of this peak remained nearly unchanged with the CoFeB thickness. This result indicates that the $\mathrm{NiFe}$ texture hardly formed in the $\mathrm{Ta} / \mathrm{MgO} / \mathrm{NiFe} / \mathrm{MgO} / \mathrm{Ta}$ films even after annealing. In contrast, an intense $\mathrm{NiFe}(111)$ peak was observed in the XRD patterns of the $\mathrm{Ta} / \mathrm{CoFeB} / \mathrm{MgO} / \mathrm{NiFe} / \mathrm{MgO} / \mathrm{CoFeB} / \mathrm{Ta}$ films after annealing. The intensity of this peak increased with the duration of the annealing process. These results suggest that the NiFe(111) texture easily formed in the $\mathrm{Ta} / \mathrm{CoFeB} / \mathrm{MgO} / \mathrm{NiFe} / \mathrm{MgO} / \mathrm{CoFeB} / \mathrm{Ta}$ films, which is crucial in optimizing the $\mathrm{MR}$ ratio of thin films.

Ta was used as a buffer layer to induce NiFe with (111) texture. A single NiFe (111) peak can be observed over the entire annealing range in $\mathrm{Ta} / \mathrm{NiFe} / \mathrm{Ta}$ films, and the intensity of the $\mathrm{NiFe}$ peak changes very little with increased annealing temperature. However, no NiFe peaks are found for as deposited $\mathrm{Ta} / \mathrm{MgO} / \mathrm{NiFe} / \mathrm{MgO} / \mathrm{Ta}$ multilayers. When films are annealed at low temperatures, the $\mathrm{NiFe}(111)$ peak is weak and changes only slightly with increased annealing temperature. A small but strong NiFe (111) peak occurs when Ta is higher than $400^{\circ}[14]$. In contrast, an intense $\mathrm{NiFe}(111)$ peak is observed in the X-ray powder diffraction (XRD) patterns of thin films containing $\mathrm{CoFeB}$ after annealing at $400{ }^{\circ} \mathrm{C}$ in $\mathrm{Ta} / \mathrm{CoFeB} / \mathrm{MgO} / \mathrm{NiFe} / \mathrm{MgO} / \mathrm{CoFeB} / \mathrm{Ta}$ films. Lee observed high thermal stability and AMR without high-temperature deposition or annealing following the use of a thin $\mathrm{NiFeCr}$ seed layer in $\mathrm{NiFe}$ films[16]. XRD results show that the NiFeCr seed layer causes the formation of large (111) textured grains in Permalloy film, and that the interface between these two layers is quite smooth. Other research has also reported that the stronger is the $\mathrm{NiFe}(111)$ texture, the higher is the AMR value[9]. 


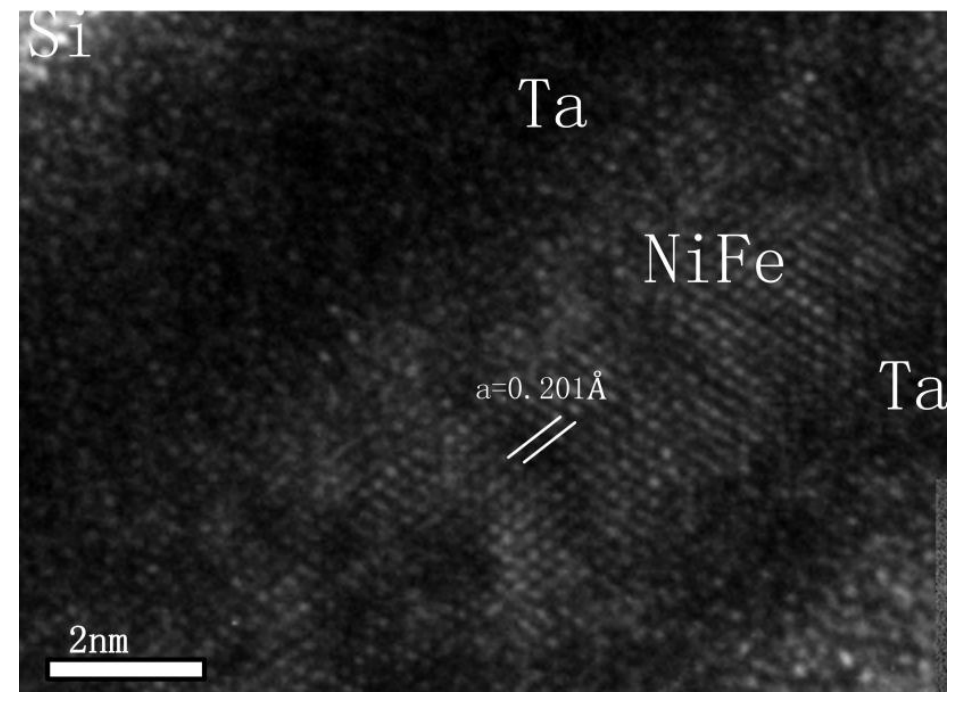

Fig.7 (A) HRTEM images of the Ta $(5 \mathrm{~nm}) / \mathrm{NiFe}(5 \mathrm{~nm}) / \mathrm{Ta}(3 \mathrm{~nm})$

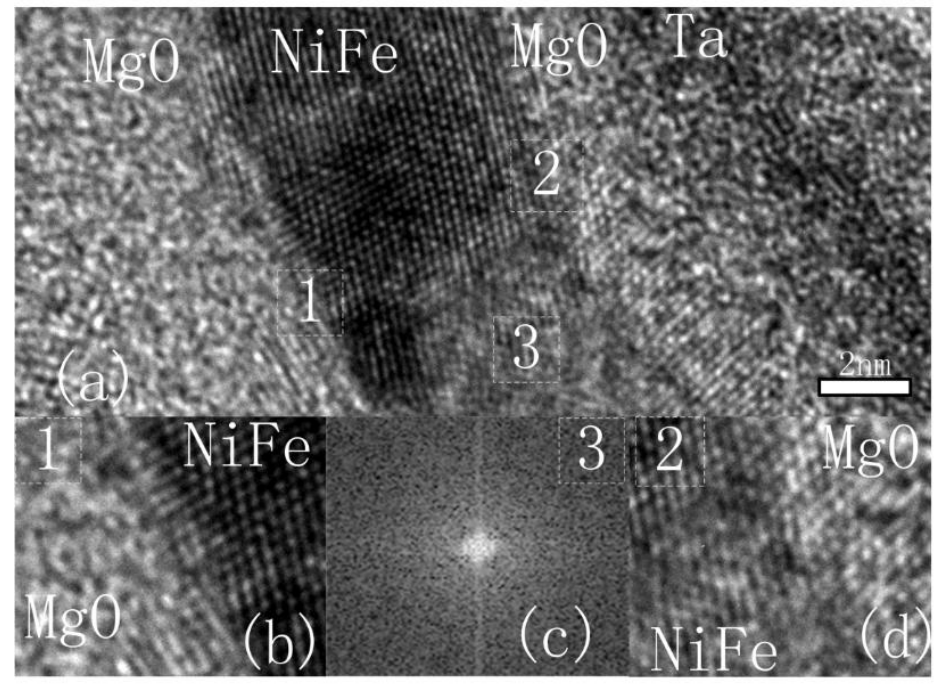

(B) HRTEM images of the $\mathrm{MgO}(3 \mathrm{~nm}) / \mathrm{NiFe}(5 \mathrm{~nm}) / \mathrm{MgO}(3 \mathrm{~nm}) / \mathrm{Ta}(3 \mathrm{~nm})$ as deposited (a), enlarged figure of part 1 (b), fast Fourier transforms of part 3, enlarged figure of part 2 (d) 


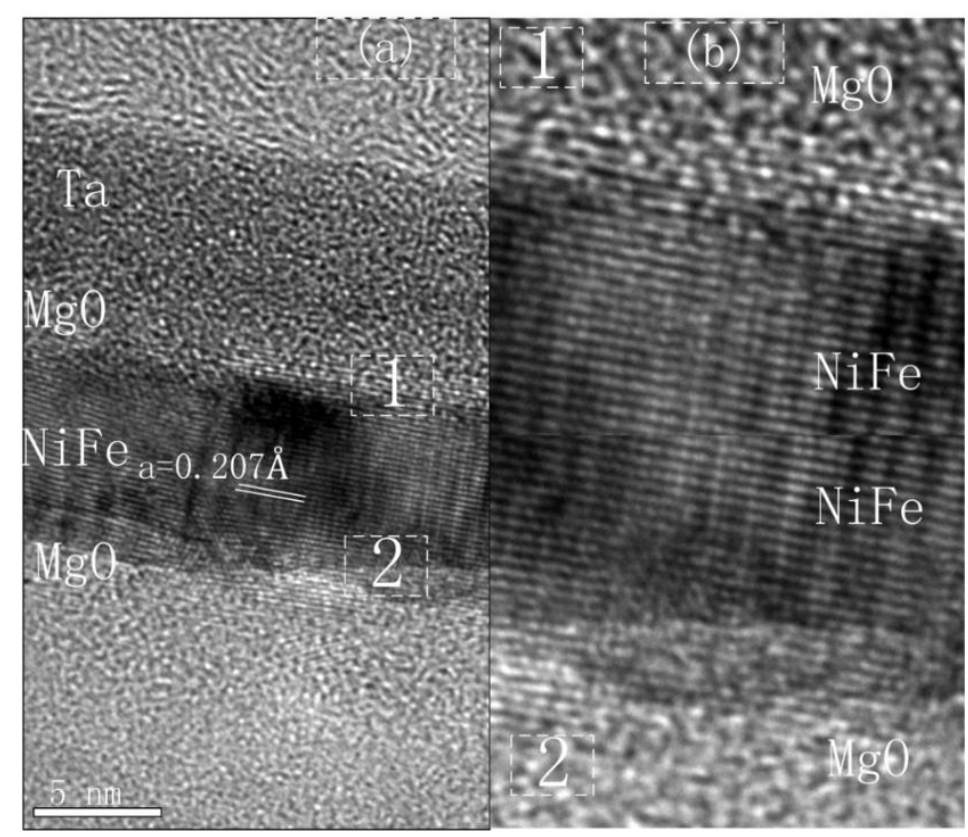

(C) HRTEM images of the $\mathrm{MgO}(3 \mathrm{~nm}) / \mathrm{NiFe}(5 \mathrm{~nm}) / \mathrm{MgO}(3 \mathrm{~nm}) / \mathrm{Ta}(3 \mathrm{~nm})$ annealed (a), enlarged figure for parts 1 and 2 (b).

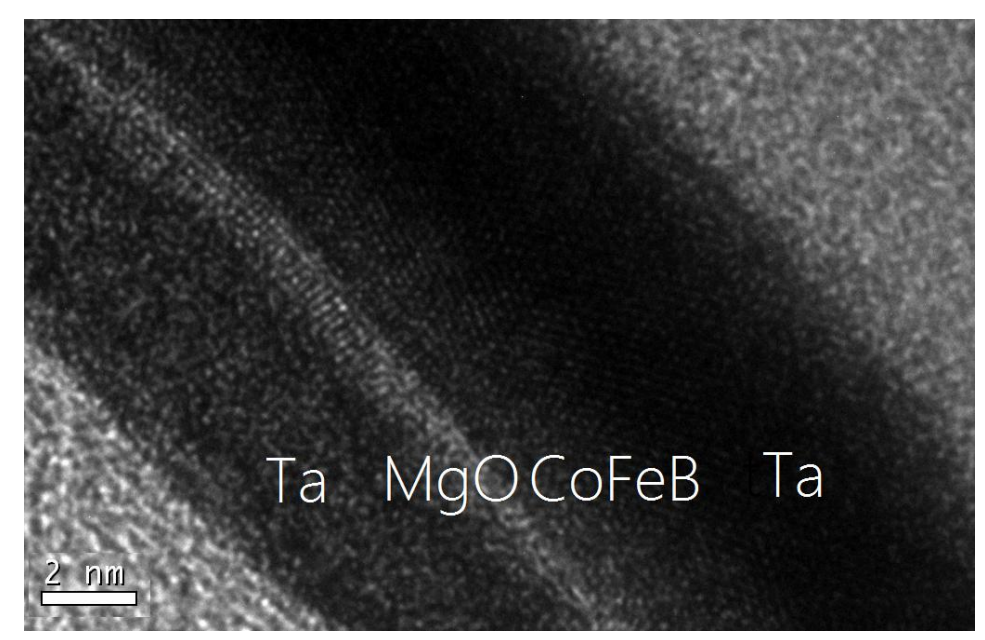

(D) HRTEM images of the $\mathrm{Ta}(5 \mathrm{~nm}) / \mathrm{CoFeB}(1 \mathrm{~nm}) \mathrm{MgO}(3 \mathrm{~nm}) / \mathrm{Ta}(3 \mathrm{~nm})$ annealed

Fig.7(A) shows HRTEM images of Ta $(5 \mathrm{~nm}) / \mathrm{NiFe}(5 \mathrm{~nm}) / \mathrm{Ta}(3 \mathrm{~nm})$. However, neither the $\mathrm{Ta} / \mathrm{NiFe}$ interface nor the $\mathrm{NiFe} / \mathrm{Ta}$ interface is obvious. Significant interface diffusions occurred between the NiFe/Ta and Ta/NiFe. Fig.7(B) and 7(C) show HRTEM images of MgO $(3 \mathrm{~nm}) / \mathrm{NiFe}(5 \mathrm{~nm}) / \mathrm{MgO}(3 \mathrm{~nm}) / \mathrm{Ta}(3 \mathrm{~nm})$ before and after annealing. In the 'as-grown' sample, we see crystalline fringes in the $\mathrm{MgO}$ layers only in the small areas shown in Fig. 7(B). After annealing, both the top and bottom $\mathrm{MgO}$ layers exhibit a much better crystalline 
structure, as shown in Fig. 7(C). However, the $\mathrm{CoFeB}$ inserted at the interface of the $\mathrm{Ta} / \mathrm{MgO}$ and $\mathrm{MgO}$ layers exhibits an fcc (100) of $\mathrm{MgO}$ textured in $\mathrm{Ta}(5 \mathrm{~nm}) / \mathrm{CoFeB}(1 \mathrm{~nm}) \mathrm{MgO}(3$ $\mathrm{nm}) / \mathrm{Ta}(3 \mathrm{~nm})$ film in Fig. 7(D). We can observe a smooth and clear $\mathrm{CoFeB} / \mathrm{MgO}$ interface. Smooth oxide/metal interfaces play a significant role in the scattering of spin-polarised electrons compared to $\mathrm{Ta} / \mathrm{NiFe} / \mathrm{Ta}$ interfaces.

HRTEM images of $\mathrm{CoFeB} / \mathrm{MgO} / \mathrm{CoFeB}$ as-deposited and after annealing were reported by Bae et al. The bottom $\mathrm{CoFeB}$ was found to be poly-crystalline in the as-deposited state, crystallizing after annealing at $340{ }^{\circ} \mathrm{C}$. The barrier interface of the $\mathrm{MgO}$ barrier became sharper and smoother after annealing. HRTEM was also used to study $\mathrm{Ta} / \mathrm{CoFeB} / \mathrm{MgO}$ thin films before and after annealing at $300{ }^{\circ} \mathrm{C}$, and a $\mathrm{MgO}$ layer was found to texture along the [001] direction [15]. HRTEM revealed a smooth, uniform and highly crystalline $\mathrm{MgO}$ barrier in $\mathrm{CoFeB} / \mathrm{MgO} / \mathrm{CoFeB} / \mathrm{Ru} / \mathrm{CoFe} / \mathrm{PtMn}$ multilayers [17], and similar results were obtained by other researchers [18-21]. Magnetic tunnel junctions based on a single crystalline $\mathrm{MgO}$ barrier with a high tunnel magnetoresistance (TMR) ratio have been extensively studied with respect to the $\mathrm{CoFeB} / \mathrm{MgO} / \mathrm{CoFeB}$ structure[22-23]. The high TMR ratio is due to coherent spin-dependent tunnelling across the single crystalline $\mathrm{MgO}$ barrier. The sharp interfaces across the $\mathrm{MgO}$ layer and its single crystallinity likely play much greater roles in specular reflection. The higher AMR ratio and sensitivity come from the significant specular reflection of electrons at both interfaces due to the crystalline $\mathrm{MgO}$ layer together with the sharp interfaces of the $\mathrm{Ta} / \mathrm{MgO} / \mathrm{NiFe} / \mathrm{MgO} / \mathrm{Ta}$. All the work described above concluded that $\mathrm{MgO}$ deposited on $\mathrm{CoFeB}$ significantly enhanced the crystallization of $\mathrm{MgO}$ and the formation of smooth interfaces. A $\mathrm{MgO}$ layer with good crystallinity and (100) orientation could significantly reduce the defects. In other words, the specular reflection of the electrons can be significantly enhanced, resulting in higher MR values. Moreover, the lattice of the $\mathrm{MgO}$ and $\mathrm{NiFe}$ layers matched well in some areas, with the $\mathrm{MgO} / \mathrm{NiFe}$ and $\mathrm{NiFe} / \mathrm{MgO}$ interfaces becoming significantly smoother after annealing [14]. The sharp interface played a critical role in the specular reflections of electrons compared to the as-grown sample. Based on the above results, it is reasonable to conclude that $\mathrm{CoFeB}$ significantly enhanced the crystallization of $\mathrm{MgO}$. This crystalline $\mathrm{MgO}$ layer, 
together with its sharp interface with the NiFe layer, resulted in an enhanced specular reflection of electrons, finally resulting in significantly higher MR ratios for $\mathrm{Ta} / \mathrm{CoFeB} / \mathrm{MgO} / \mathrm{NiFe} / \mathrm{MgO} / \mathrm{CoFeB} / \mathrm{Ta}$ multilayers.

In $\mathrm{Ta} / \mathrm{NiFe} / \mathrm{Ta}$ films, magnetic dead layers occur at the $\mathrm{Ta} / \mathrm{NiFe}$ and $\mathrm{NiFe} / \mathrm{Ta}$ interfaces, which decrease the effective thickness of the NiFe layer [13]. As reported by Ding, the AMR of $\mathrm{NiFe}$ films with a $\mathrm{Ta} / \mathrm{MgO} / \mathrm{NiFe} / \mathrm{MgO} / \mathrm{Ta}$ structure can be significantly enhanced by the $\mathrm{MgO}$ layer. The $\mathrm{MgO}$ layers suppress the formation of magnetic dead layers and prevent interdiffusions between the NiFe and Ta layers [14]. In this letter, we report our results from a study of the effect of $\mathrm{CoFeB}$ insertion layers in $\mathrm{Ta} / \mathrm{CoFeB} / \mathrm{MgO} / \mathrm{NiFe} / \mathrm{MgO} / \mathrm{CoFeB} / \mathrm{Ta}$. We found the $\mathrm{CoFeB} / \mathrm{MgO}$ layers to effectively eliminate the formation of interfacial magnetic dead layer and to suppress the thermally driven interdiffusion between $\mathrm{Ta}$ and $\mathrm{NiFe}$.

\section{Conclusions}

$\mathrm{Ta} / \mathrm{CoFeB} / \mathrm{MgO} / \mathrm{NiFe} / \mathrm{MgO} / \mathrm{CoFeB} / \mathrm{Ta}$ thin films were prepared and annealed. $\mathrm{CoFeB}$ layers with a thickness of $1.5 \mathrm{~nm}$ in thin films containing a 10-nm NiFe layer significantly enhanced the AMR after annealing at $400{ }^{\circ} \mathrm{C}$ for $2 \mathrm{~h}$ (i.e. the MR ratio increased from $2.74 \%$ to $3.56 \%$ ). The hysteresis loops revealed fine soft magnetism and uniaxial anisotropy in the thin films, with $\mathrm{H}_{\mathrm{c}}$ and $\mathrm{H}_{\mathrm{s}}$ reaching 2 and $5 \mathrm{Oe}$, respectively. The $\mathrm{CoFeB} / \mathrm{MgO}$ layers suppressed the formation of the magnetic dead layers and increased the effective thickness of NiFe. More importantly, the single $\mathrm{NiFe}(111)$ peak observed in the XRD profiles of thin films containing $\mathrm{CoFeB}$ was indicative of higher AMR values. XRD revealed that the $\mathrm{NiFe}(111)$ texture easily formed in the $\mathrm{Ta} / \mathrm{CoFeB} / \mathrm{MgO} / \mathrm{NiFe} / \mathrm{MgO} / \mathrm{CoFeB} / \mathrm{Ta}$ films, resulting in thin films with enhanced $\mathrm{MR}$ and magnetic properties. $\mathrm{CoFeB}$ significantly enhanced the crystallization of $\mathrm{MgO}$, and this crystalline $\mathrm{MgO}$ layer, together with its sharp interface with the NiFe layer, resulted in a significant specular reflection of electrons. All these factors together resulted in higher AMR values for the studied thin films.

\section{Acknowledgments}

The present work was supported by the National Science Foundation of China (Grant No. 51101012 and 51371025) and the Fundamental Research Funds for the Central Universities 


\section{References}

[1]I. Mateos, J. Ramos-Castro, A. Lobo, Low-frequency noise characterization of a magnetic field monitoring system using an anisotropic magnetoresistance, Sensors \& Actuators A Physical. 235(2016)57-63.

[2]S. Wang, H. Zhang, Y. Yao, Effects of NiO Layer on Anisotropic Magnetoresistance and Sensitivity of Ni81Fe19 Films, Journal of Electronic Materials. 43(9)(2014)3493-3498.

[3]M. Carlos, C. Carolina, M. Alberto, G. Alfonso, G. Mercedes, Magnetic Sensors Based on Amorphous Ferromagnetic Materials: A Review, Sensors.15(11)(2015) 28340-28366.

[4]S. Ziętek, M. Cecot, W. Skowroński, T. Stobiecki, Magnetization dynamics of NiFe film and anisotropic magnetoresistance device: Comparison of microwave detection methods, International Conference on Microwave. 2016

[5]C. Morón, A. Garcia, E. Tremps, J.A. Somolinos, Anisotropic Magnetoresistive Study in Bilayer NiFe-NiO for Sensor Applications, Key Engineering Materials. 543(2013)167-170.

[6]D. Atkinson, S. Searle, M. Jefferies, J. Levy, H. Cramman, Controlling Anisotropy of NiFe Thin Films During Deposition for Device Applications, Sensor Lett. 11(1)(2013)13-20.

[7]T. R. McGuire and R. I. Potter, Anisotropic Magneto-resistance in Ferromagnetic 3d Alloys, IEEE Trans. Magn. 29(4)(1975)1018-1038.

[8]Y. F. Liu, J. W. Cai, L. Sun, Large enhancement of anisotropic magnetoresistance and thermal stability in Ta/NiFe/Ta trilayers with interfacial Pt addition, Appl. Phys. Lett. 96(2010) 092509.

[9]L. Ding, J. Teng, Q. Zhan, C. Feng, M.H. Li, Gang Han, L.J. Wang, G.H. Yu, S.Y. Wang, Enhancement of the magnetic field sensitivity in Al 2 O 3 encapsulated NiFe films with anisotropic magnetoresistance, Appl. Phys. Lett. 94 (2009)162506.

[10] S. Y. Wang, T. J. Gao, C. T. Wang, J.F. He, Studies of anisotropic magnetoresistance and magnetic property of $\mathrm{Ni}_{81} \mathrm{Fe}_{19}$ ultra-thin films with the lower base vacuum, Journal of Alloys and Compounds. 696 (2017) 234-238.

[11]Q.H. Lu, R. Huang, L.S. Wang, Z.G. Wu, C. Li, Q. Luo, S.Y. Zuo, J. Li, D.L. Peng, G.L. Han, P.X. Yan, Thermal annealing and magnetic anisotropy of NiFe thin films on $\mathrm{n}+-\mathrm{Si}$ for spintronic device applications, Journal of Magnetism \& Magnetic Materials. 394(2015)253-259.

[12]H. Funaki , S. Okamoto , O. Kitakami , Y. Shimada,Improvement in Magnetoresistance of Very Thin Permalloy Films by Post-Annealing, Japanese Journal of Appl. Phys. 33(9B)(1994)L1304-L1306

[13]G. H.Yu, M.H. Li， J. Teng, F.W. Zhu, W.Y. Lai,Interface reactions in Ta/NiFe/Ta structures and their influence on magnetic properties, Thin Solid Films. 484(1-2)(2005)208-214.

[14]L. Ding, J. Teng, X. C. Wang, C. Feng, Y. Jiang, G. H. Yu, S. G. Wang, and R. C. C. Ward, Designed synthesis of materials for high-sensitivity geomagnetic sensors, Appl. Phys. Lett. 96(2010)052515.

[15]J.Y. Bae, W.C. Lim, H.J. Kim, T.D. Lee, K.W. Kim,T. W. Kim,Compositional change 
of $\mathrm{MgO}$ barrier and interface in $\mathrm{CoFeB} / \mathrm{MgO} / \mathrm{CoFeB}$ tunnel junction after annealing, Journal of Appl. Phys. 99(8)(2006)25-29.

[16]W.Y. Lee, M.F. Toney, D. Mauri, High magnetoresistance in sputtered Permalloy thin films through growth on seed layers of (Ni0.81Fe0.19)1-xCrx, IEEE Transactions on Magnetics. 36(1)(2000)381-385.

[17]J. Sinha, M.Gruber, M. Kodzuka, T. Ohkubo, S. Mitani, K. Hono, and M. Hayashia, Influence of boron diffusion on the perpendicular magnetic anisotropy in $\mathrm{Ta} / \mathrm{CoFeB} / \mathrm{MgO}$ ultrathin films, Journal of Appl. Phys. 117 (2015)043913.

[18]S. V. Karthik, Y. K. Takahashi, T. Ohkubo, K. Hono, H. D. Gan, S. Ikeda, H. Ohno, Transmission electron microscopy study on the effect of various capping layers on $\mathrm{CoFeB} / \mathrm{MgO} / \mathrm{CoFeB}$ pseudo spin valves annealed at different temperatures, Journal of Appl. Phys. 111(2012) 083922.

[19]T. Miyajima, T. Ibusuki, S. Umehara, M.e Sato, S. Eguchi, M. Tsukada, Y. Kataoka, Transmission electron microscopy study on the crystallization and boron distribution of $\mathrm{CoFeB} / \mathrm{MgO} / \mathrm{CoFeB}$ magnetic tunnel junctions with various capping layers, Appl. Phys. Lett. 94 (2009)122501.

[20]A. Cerezo, A. K. Petford-Long, D. Mauri, L. Folks, and M. J. Carey, Three-dimensional atom probe investigation of boron distribution in $\mathrm{Co} F \mathrm{Be} / \mathrm{Mg} \mathrm{O} / \mathrm{Co} \mathrm{Fe}$ B magnetic tunnel junctions, Appl. Phys. Lett. 93 (2008)071901.

[21]W. X. Wang, Y. Yang, H. Naganuma, Y. Ando, R. C. Yu, and X. F. Han, The perpendicular anisotropy of $\mathrm{Co} 40 \mathrm{Fe} 40 \mathrm{~B} 20$ sandwiched between $\mathrm{Ta}$ and $\mathrm{MgO}$ layers and its application in $\mathrm{CoFeB} / \mathrm{MgO} / \mathrm{CoFeB}$ tunnel junction, Appl. Phys. Lett. 99(2011) 012502.

[22] S. S. P. Parkin, C. Kaiser, A. Panchula, P. M. Rice, B. Hughes, M. Samant, S. H. Yang, Giant tunnelling magnetoresistance at room temperature with $\mathrm{MgO}$ (100) tunnel barriers, Nature Mater. 3(2004)862.

[23] M.S. Jeon, K.S. Chae, D.Y. Lee, Y. Takemura, S.E. Lee, T.H. Shima, J.G. Park,The dependency of tunnel magnetoresistance ratio on nanoscale thicknesses of Co2Fe6B2 free and pinned layers for $\mathrm{Co} 2 \mathrm{Fe} 6 \mathrm{~B} 2 / \mathrm{MgO}$-based perpendicular-magnetic-tunnel-junctions, Nanoscale, 7 (2015) 8142. 